\title{
Symmetrical drug-related intertriginous and flexural exanthema (baboon syndrome) caused by cotrimoxazole
}

\section{Symetryczna wyprzeniowa i zgięciowa osutka polekowa (zespół pawiana) wywołana kotrimoksazolem}

\author{
B.J. Government Medical College, Pune, Maharashtra, India \\ B.J. Government Medical College, Pune, Maharashtra, Indie
}

Neelam Bhatt, Ravindranath B. Chavan, Nitika S. Deshmukh, Vasudha A. Belgaumkar

\author{
CORRESPONDING AUTOR/ \\ ADRES DO KORESPONDENCJI: \\ MD (DVL) Dr. Ravindranath \\ B. Chavan \\ B.J. Government Medical College \\ Jai Prakash Narayan Road \\ Near Railway Station \\ Pune, Maharashtra, India 411001 \\ e-mail: \\ drravindranathchavan@gmail.com
}

\begin{abstract}
Introduction. Symmetrical drug-related intertriginous and flexural exanthema (SDRIFE or baboon syndrome) is an uncommon form of systemic contact dermatitis, readily differentiated from other drug eruptions by its peculiar appearance.

Case report. A 48-year-old male presented with itchy erythematous rash with blisters two days after taking an unknown drug. Dermatological examination revealed symmetrical erythematous macules with large bullae over the anterior trunk, neck, inner thighs and axillae. Systemic examination and laboratory parameters were normal. A diagnosis of symmetrical drug-related intertriginous and flexural exanthema associated with cotrimoxazole was made based on dermatological findings, histopathology and the reappearance of lesions after administration of cotrimoxazole (trimethoprim $160 \mathrm{mg}$ and sulfamethoxazole $800 \mathrm{mg}$ twice daily). Coincidentally, he was detected to be HIV seropositive and started a highly active antiretroviral therapy. His skin lesions resolved with systemic glucocorticosteroids.
\end{abstract}

Conclusions. Patients and clinicians should be aware of the possibility of a baboon syndrome due to cotrimoxazole, a widely used drug.

\section{STRESZCZENIE}

Wprowadzenie. Symetryczna wyprzeniowa i zgięciowa osutka wywołana lekiem (zespół pawiana) jest rzadką postacią systemowego kontaktowego zapalenia skóry, którą odróżnia się od innych zmian polekowych na podstawie obrazu klinicznego.

Opis przypadku. Mężczyzna w wieku 48 lat zgłosił się do poradni z powodu rumieniowych i pęcherzowych zmian skórnych, które wystąpiły po 2 dniach od przyjęcia nieznanego leku. Badanie dermatologiczne ujawniło na skórze rumieniowe plamy oraz duże pęcherze umiejscowione symetrycznie na przedniej części tułowia i szyi, na wewnętrznych powierzchniach ud oraz w dołach pachowych. Badanie ogólne oraz badania laboratoryjne nie wykazały nieprawidłowości. Na podstawie wyników oceny dermatologicznej i histopatologicznej oraz wystąpienia identycznych zmian skórnych po zastosowaniu kotrimoksazolu (trimetoprim $160 \mathrm{mg}$ i sulfametoksazol $800 \mathrm{mg} 2$ razy dziennie) rozpoznano symetryczną wyprzeniową i zgięciową osutkę wywołaną kotrimoksazolem. W trakcie diagnostyki stwierdzono u pacjenta dodatni wynik testu serologicznego w kierunku HIV i wdrożono terapię przeciwretrowirusową. 
Zmiany skórne ustąpiły po zastosowaniu ogólnoustrojowego leczenia glikokortykosteroidami.

Wnioski. Zwracamy uwagę na możliwość wystąpienia zespołu pawiana podczas leczenia kotrimoksazolem, który jest powszechnie stosowanym lekiem.

Key words: symmetrical drug-related intertriginous and flexural exanthema, baboon syndrome, cotrimoxazole.

Słowa kluczowe: symetryczna wyprzeniowa i zgięciowa osutka polekowa, zespół pawiana, kotrimoksazol.

\section{INTRODUCTION}

Symmetrical drug-related intertriginous and flexural exanthema (SDRIFE), previously called the baboon syndrome is characterized by erythema over the flexural and intertriginous areas with involvement of at least one large body fold. It is most commonly associated with the use of $\beta$-lactam antibiotics [1].

\section{OBJECTIVE}

We are reporting a case of SDRIFE due to cotrimoxazole to emphasize that clinicians should be aware of this unusual cutaneous side effect of cotrimoxazole.

\section{CASE REPORT}

A 48-year-old male presented with sudden onset blisters over the body 2 days after taking some unknown drug for throat pain from a quack. Within 45 hours of drug consumption, he developed itching and burning over flexural areas followed by appearance of rash. He denied past history of similar episodes or any topical applications. Dermatological examination revealed multiple symmetrical ill- to well-defined erythematous macules and erosions with large flaccid bullae over the lateral aspect of the trunk extending beyond to involve the trunk, neck, inner thighs (in a V fashion) and bilateral axillary region (fig. $1 \mathrm{~A}$ ). Mucosae, palms and soles were normal. Systemic examination was unremarkable. Differential diagnoses considered were SDRIFE and bullous fixed drug eruption. Laboratory and radiological examinations were unremarkable except for HIV positivity on ELISA. Skin histopathology showed partial detachment of superficial layers (subcorneal) with mild spongiosis, irregular acanthosis and sparse perivascular mononuclear cells infiltrate without eosinophils which was consistent with SDRIFE (fig. 1 B).

The skin lesions markedly improved within a week of treatment with oral prednisolone (40 mg/day) and

\section{WPROWADZENIE}

Symetryczna wyprzeniowa i zgięciowa osutka wywołana lekiem (symmetrical drug-related intertriginous and flexural exanthema - SDRIFE), określana wcześniej jako zespół pawiana, charakteryzuje się występowaniem na skórze zmian rumieniowych umiejscowionych w okolicach wyprzeniowych i zgięciowych z zajęciem co najmniej jednego dużego fałdu skórnego. Pojawia się najczęściej po przyjęciu przez pacjenta leku z grupy antybiotyków $\beta$-laktamowych [1].

\section{CEL PRACY}

Opisujemy przypadek SDRIFE po zastosowaniu kotrimoksazolu w celu zwrócenia uwagi na nietypowe skórne objawy niepożądane kotrimoksazolu.

\section{OPIS PRZYPADKU}

Mężczyzna 48-letni zgłosił się do poradni z powodu pęcherzowych zmian skórnych o nagłym początku, po 2 dniach od przyjęcia nieznanego leku na ból gardła otrzymanego od znachora. W ciągu 4-5 godzin od zastosowania leku u pacjenta wystąpił świąd i uczucie pieczenia skóry w okolicach zgięciowych, a następnie pojawiły się wykwity skórne. Według pacjenta podobne objawy nie występowały w przeszłości. Chory nie stosował miejscowo żadnych leków. W badaniu dermatologicznym stwierdzono obecność licznych symetrycznie rozmieszczonych, od słabo do wyraźnie odgraniczonych plam rumieniowych i nadżerek z dużymi, wiotkimi pęcherzami. Zmiany umiejscowione były na bocznej części tułowia i rozciągały się na pozostałą powierzchnię skóry tułowia, szyję, wewnętrzną powierzchnię ud (w kształcie litery "V") oraz występowały obustronnie w okolicy pachowej (ryc. 1 A). Nie stwierdzono nieprawidłowości w obrębie błon śluzowych i skóry dłoni oraz podeszew, a także zmian ogólnoustrojowych. W rozpoznaniu różnicowym stwierdzono pęcherzową osutkę polekową. Badania laboratoryjne i radiologiczne 

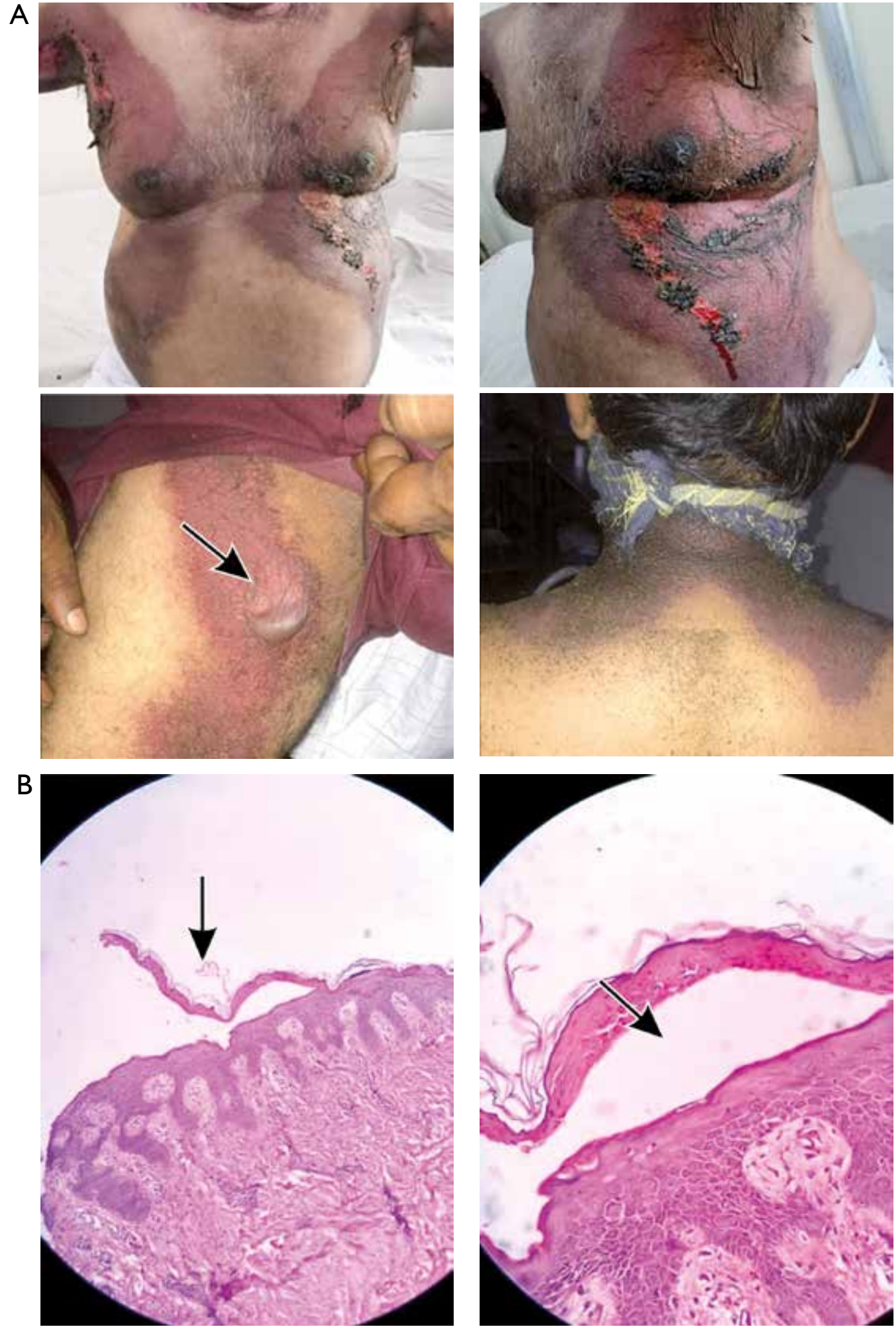

Figure I. A - Erythematous macules and erosions with large bullae over the anterior aspect of the trunk, collar of the neck, inner thighs and bilateral axillary region. B - Partial detachment of superficial layers (subcorneal) with mild spongiosis, irregular acanthosis $(H+E$, $10 \times, 40 \times)$

Rycina I. A - Plamy rumieniowe i nadżerki oraz duże pęcherze w obrębie przodu tułowia i szyi, na wewnętrznej części ud i obustronnie w okolicy pach. B - Częściowe odwarstwienie powierzchownych warstw naskórka (podrogowo) z łagodną spongiozą, nieregularna akantoza (barwienie $\mathrm{H}+\mathrm{E}, \mathrm{I0} \times, 40 \times$ ) 
resolved with post-inflammatory hypopigmentation (fig. 2). The patient also started a highly active antiretroviral therapy (HAART) TLE regimen (tenofovir $300 \mathrm{mg}+$ lamivudine $300 \mathrm{mg}+$ efavirenz $600 \mathrm{mg}$ once daily) along with cotrimoxazole (trimethoprim $160 \mathrm{mg}$ and sulfamethoxazole $800 \mathrm{mg}$ twice daily) as a part of the prophylaxis protocol for HIV-related infections. Following ingestion of cotrimoxazole, the patient developed itching, and reappearance of erythematous macules with multiple vesicles over the previously affected sites within 5 to 6 hours (fig. 3). Cotrimoxazole was discontinued immediately and the dose of prednisolone was increased to $40 \mathrm{md}$ /day again. He was counselled to avoid cotrimoxazole and all sulfa drugs in the future. HAART was continued without any complications or side effects.

Hence a final diagnosis of SDRIFE due to cotrimoxazole was confirmed based on clinical criteria as mentioned in the discussion.

\section{DISCUSSION}

Symmetrical drug-related intertriginous and flexural exanthema (SDRIFE) is a symmetrical erythe- nie wykazały nieprawidłowości poza dodatnim wynikiem testu ELISA w kierunku zakażenia HIV. W badaniu histopatologicznym skóry stwierdzono częściowe odwarstwienie powierzchownych warstw naskórka (podrogowo) i niewielką spongiozę, a także nieregularną akantozę i rozproszony naciek okołonaczyniowy z komórek jednojądrzastych bez eozynofilów. Obraz ten wskazywał na SDRIFE (ryc. 1 B).

Zmiany skórne uległy znaczącemu ograniczeniu w czasie tygodnia od wdrożenia doustnego leczenia prednizolonem (40 mg/dobę) i ustąpiły, pozostawiając odbarwienia pozapalne (ryc. 2). U pacjenta zastosowano również HAART (highly active antiretroviral therapy) w schemacie TLE (tenofowir $300 \mathrm{mg}+$ lamiwudyna $300 \mathrm{mg}$ + efawirenz $600 \mathrm{mg}$ raz dziennie) z kotrimoksazolem (trimetoprim $160 \mathrm{mg}$ i sulfametoksazol $800 \mathrm{mg} 2$ razy dziennie) zgodnie z protokołem profilaktyki zakażeń związanych z HIV. Po przyjęciu kotrimoksazolu u pacjenta wystąpił świąd, a w czasie 5-6 godzin na skórze ponownie pojawiły się plamy rumieniowe z licznymi pęcherzykami w okolicach uprzednio zajętych przez zmiany skórne (ryc. 3). Niezwłocznie odstawiono kotrimoksazol i ponownie zwiększono dawkę prednizolonu do 40 m/dobę. Pacjentowi zalecono unikanie kotrimo-
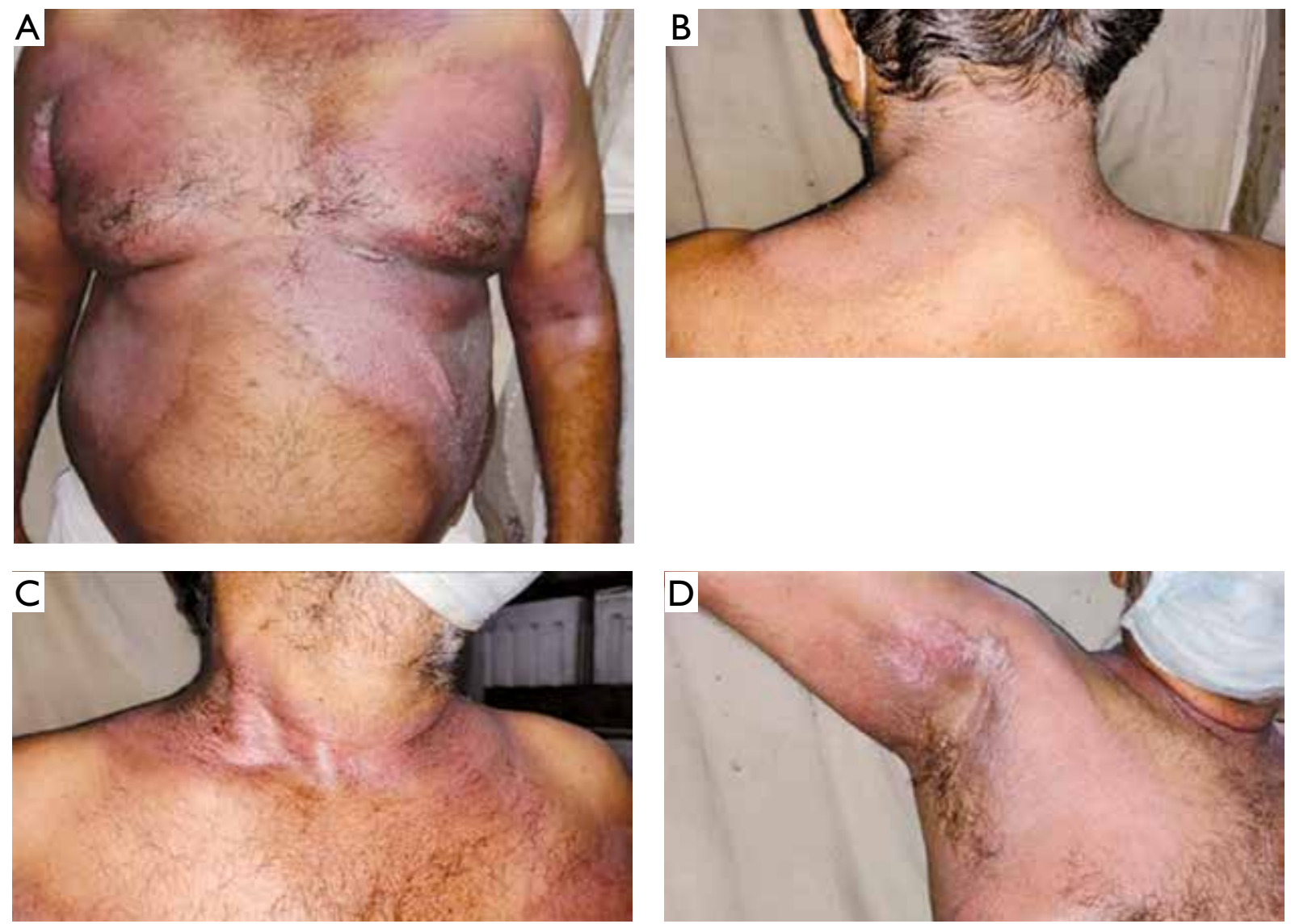

Figure 2. Improvement in skin lesions with post inflammatory hypo-pigmentation

Rycina 2. Poprawa stanu skóry, widoczne odbarwienia pozapalne 

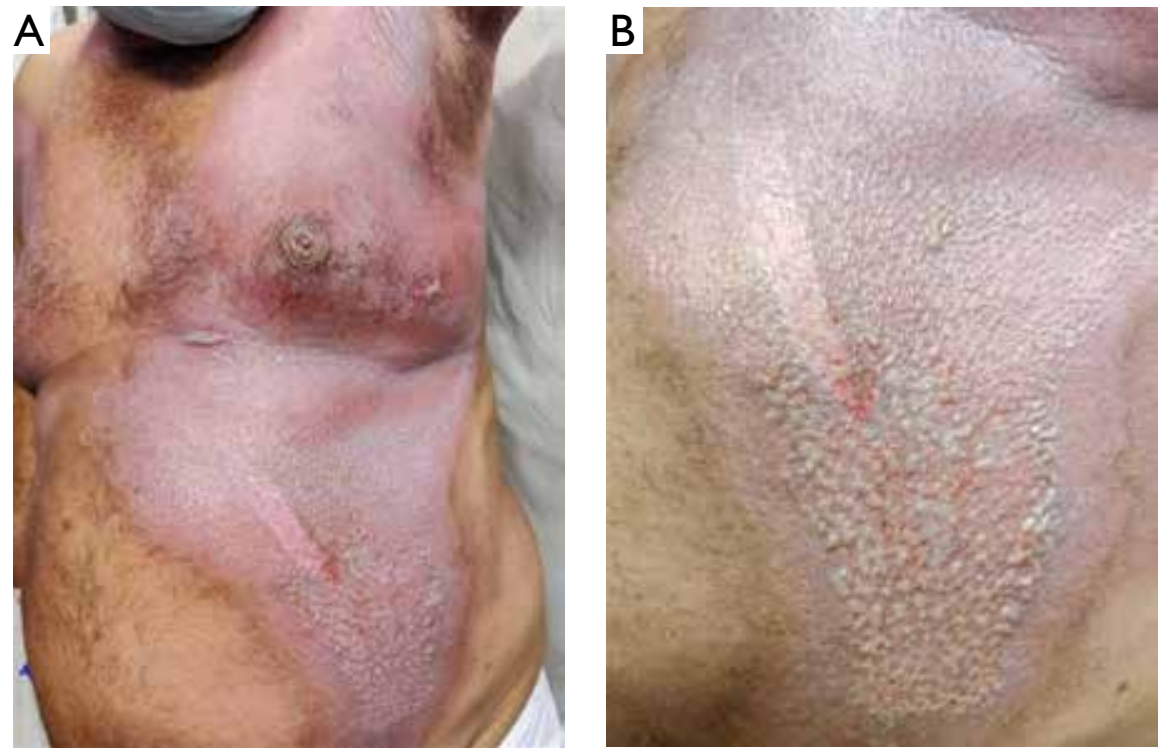

Figure 3. Reappearance of erythematous macules with multiple vesicles over the previous sites

Rycina 3. Ponowne wystąpienie rumieniowych plam z licznymi pęcherzykami w obszarach uprzednio zajętych

matous rash on the gluteal and intertriginous areas observed after exposure to systemic drugs [2]. Previously, in 1984, it was referred to as the baboon syndrome, due to the distribution of the lesions localized on the buttocks and inner thighs (resembling the red rump of baboons), and observed as a response to systemic or local administration of contact allergens and drugs [3]. Hausermann proposed the term SDRIFE in 2004 as more appropriate for those reactions occurring after exposure to systemic drugs, regardless of prior sensitization [4]. It is distinct from other cutaneous drug reactions due to its typical morphology, distribution, and the absence of systemic findings.

SDRIFE is not very common, and the literature documents a limited number of cases. Exact pathogenetic mechanisms are still unclear, but it has been suspected to develop as a result of a type IV delayed hypersensitivity immune response.

Among the offending medications are $\beta$-lactam antibiotics; especially amoxicillin (most common), non- $\beta$-lactam antibiotics (pristinamycin, clindamycin, erythromycin, roxithromycin, cotrimoxazole), other anti-infective agents (nystatin, terbinafine, nystatin, fluconazole, metronidazole, and valacyclovir), other drugs including codeine, pseudoephedrine, cimetidine, allopurinol, heparin, hydroxyurea, oxycodone, naproxen, risperidone, ethyl loflazepate, antihypertensives, iodine radio-contrast media, chemotherapeutic agents, monoclonal antibodies such as infliximab and topical agents (bufexamac, 5-fluorouracil) [4-6]. Our patient developed SDRIFE due to cotrimoxazole, an unusual cause for this particular adverse cutaneous drug reaction. Very few cases of SDRIFE due to cotrimoxazole use are reported in the literature [7]. ksazolu i wszystkich leków z grupy sulfonamidów. Terapię HAART kontynuowano bez powikłań i działań ubocznych.

Ostateczne rozpoznanie SDRIFE wywołanego kotrimoksazolem zostało potwierdzone na podstawie kryteriów klinicznych przedstawionych poniżej.

\section{OMÓWIENIE}

Symetryczna wyprzeniowa i zgięciowa osutka wywołana lekiem ma postać wykwitów rumieniowych rozmieszczonych symetrycznie na skórze pośladków i w okolicach wyprzeniowych, które pojawiają się po ekspozycji na stosowane ogólnie leki [2]. W 1984 r. schorzenie określono jako zespół pawiana ze względu na charakterystyczną lokalizację zmian na pośladkach i wewnętrznej powierzchni ud (przypominają czerwony zad pawianów). Zaobserwowano, że objawy pojawiają się w odpowiedzi na ogólnoustrojowe lub miejscowe podawanie alergenów o działaniu kontaktowym i leków [3]. W 2004 r. Hausermann zaproponował termin SDRIFE jako bardziej odpowiednie określenie reakcji zachodzących po ekspozycji na ogólnie stosowane leki niezależnie od wcześniejszego uczulenia [4]. SDRIFE różni się od innych skórnych reakcji polekowych charakterystycznymi cechami morfologicznymi i rozmieszczeniem zmian oraz brakiem nieprawidłowości ogólnoustrojowych.

Zespół pawiana jest rzadkim schorzeniem, w piśmiennictwie można znaleźć niewiele opisów przypadków. Dokładny mechanizm patogenetyczny schorzenia nie jest w pełni poznany, jednak przypuszcza się, że ma on związek z immunologiczną reakcją nadwrażliwości opóźnionej typu IV. 
The diagnosis of SDRIFE encompasses five criteria: 1) exposure to a systemically administered drug either for the first time or with repeated doses (excluding contact allergens), 2) sharply demarcated erythema of the gluteal/perianal area and/or V-shaped erythema of the inguinal/perigenital area, 3) involvement of at least another intertriginous/flexural localization, 4) symmetry of the affected areas, and 5) absence of systemic symptoms and signs [4]. Our patient fulfilled all 5 criteria. As mentioned earlier, our patient had a sharply demarcated rash which was V-shaped over the inguinal region with symmetric involvement of multiple flexural sites (axillae, inner thighs, and neckline). Moreover, re-appearance of the rash on administration of the suspected drug (cotrimoxazole) (fig. 3) can be considered as an inadvertent positive drug provocation test which clinched the diagnosis.

Skin lesions of SDRIFE are often reported as maculopapular erythema or plaques. Atypical manifestations like pustules, papules, blisters and, purpuric lesions have also been described in rare cases [8]. The differential diagnosis includes fixed drug eruption, toxic erythema of chemotherapy, acute generalized exanthematous pustulosis, and drug rash with eosinophilia and systemic symptoms (DRESS). SDRIFE typically does not present with mucosal involvement, and occurrence of lesions on the face and palmoplantar surfaces is very uncommon [8]. The histopathology of SDRIFE demonstrates predominantly superficial perivascular mononuclear cells; occasionally extravasated erythrocytes, neutrophils, and eosinophils with mild dermal oedema and slight spongiosis may be seen. Rarely, the pathology can mimic acute generalized pustular dermatosis, bullous drug eruptions (such as erythema multiforme and fixed drug eruption), lichenoid dermatitis, leukocytoclastic vasculitis, or neutrophilic dermatoses.

The diagnosis of SDRIFE relies mostly on the clinical presentation and history with exclusion of other causes of the rash. Treatment revolves around discontinuation of the offending agent and initiation of topical or systemic corticosteroids.

\section{CONCLUSIONS}

Symmetrical drug-related intertriginous and flexural exanthema is an uncommon drug reaction that can easily be missed unless the temporal relationship between the drug intake and the nature of the skin eruption is well established. This implies that the actual incidence of SDRIFE is probably higher than previously thought. Considering the widespread use of cotrimoxazole in a developing country like India, patients should always be aware of the possibility of a drug reaction and consult their doctor immediately on developing a rash after consumption of any drug.
Wśród leków, które mogą wywoływać zaburzenie, wymieniane są antybiotyki $\beta$-laktamowe, a zwłaszcza amoksycylina (najczęściej), antybiotyki nie- $\beta$-laktamowe (pristynamycyna, klindamycyna, erytromycyna, roksytromycyna, kotrimoksazol), leki przeciwzakaźne (nystatyna, terbinafina, flukonazol, metronidazol i walacyklowir), inne leki, m.in. kodeina, pseudoefedryna, cymetydyna, allopurynol, heparyna, hydroksymocznik, oksykodon, naproksen, risperidon, loflazepinian etylu, leki przeciwnadciśnieniowe, jodowe środki cieniujące, leki chemioterapeutyczne, przeciwciała monoklonalne - m.in. infliksymab, oraz środki stosowane miejscowo (bufeksamak, 5-fluorouracyl) [4-6]. U opisywanego przez nas pacjenta wystąpienie SDRIFE miało związek z przyjęciem kotrimoksazolu, co stanowi nietypową przyczynę tej swoistej skórnej reakcji polekowej. W piśmiennictwie opisano bardzo niewiele przypadków SDRIFE wywołanych przez kotrimoksazol [7].

Rozpoznanie SDRIFE opiera się na 5 kryteriach: 1) ekspozycja na lek podawany ogólnie po raz pierwszy lub w dawkach powtarzanych (z wyłączeniem alergenów kontaktowych), 2) ostro odgraniczone zmiany rumieniowe w okolicy pośladkowej/okołoodbytniczej i/lub rumień w kształcie litery "V” umiejscowiony w okolicy pachwinowej/okołogenitalnej, 3) zajęcie co najmniej jednej innej okolicy wyprzeniowej/zgięciowej, 4) symetryczne rozmieszczenie zmian skórnych, 5) brak ogólnoustrojowych objawów przedmiotowych i podmiotowych [4]. Opisywany przez nas pacjent spełniał wszystkie 5 kryteriów. Jak wspomniano wcześniej, u mężczyzny występowały wykwity ostro odgraniczone od otaczającej skóry w układzie przypominającym literę "V", umiejscowione w rejonie pachwin, z symetrycznym zajęciem licznych okolic zgięciowych (pachy, wewnętrzna strona ud i szyja). Ponadto ponowne pojawienie się zmian skórnych po podaniu podejrzewanego leku (kotrimoksazolu) (ryc. 3) można uznać za dodatni wynik niezamierzonego testu prowokacyjnego, który umożliwił ostateczne rozpoznanie.

Zmiany skórne w przebiegu SDRIFE są często określane jako rumień plamisto-grudkowy lub wykwity w postaci blaszek. W rzadkich przypadkach opisywano również nietypowe wykwity skórne, m.in. krostki, grudki, pęcherze i zmiany plamicze [8]. Diagnostyka różnicowa obejmuje rumień trwały, rumień wywołany toksycznym działaniem chemioterapii, ostrą uogólnioną osutkę krostkową oraz zespół DRESS. W przebiegu SDRIFE zazwyczaj nie obserwuje się zajęcia błon śluzowych, a zmiany skórne na twarzy, dłoniach i podeszwach występują bardzo rzadko [8]. W obrazie histopatologicznym SDRIFE widoczna jest przewaga powierzchownych okołonaczyniowych komórek jednojądrzastych ze sporadycznie występującymi wynaczynionymi erytrocytami, neutrofilami 


\section{CONFLICT OF INTEREST}

The authors declare no conflict of interest. i eozynofilami, łagodny obrzęk skóry i nieznacznie nasilona spongioza naskórka. Rzadko przebieg zaburzenia może naśladować ostrą uogólnioną dermatozę krostkową, pęcherzowe osutki polekowe (m.in. rumień wielopostaciowy i rumień trwały), zmiany liszajopodobne, leukocytoklastyczne zapalenie naczyń lub dermatozy neutrofilowe.

Rozpoznanie SDRIFE opiera się głównie na obrazie klinicznym i danych $z$ wywiadu oraz wykluczeniu innych przyczyn zmian skórnych. Leczenie polega na odstawieniu leku odpowiedzialnego za wystąpienie zmian skórnych oraz miejscowym lub ogólnym podawaniu glikokortykosteroidów.

\section{WNIOSKI}

Symetryczna wyprzeniowa i zgięciowa osutka polekowa jest rzadko występującą reakcją na lek. Może stanowić wyzwanie diagnostyczne w przypadkach, w których trudno jest ustalić bezpośrednią zależność czasową między przyjęciem leku i pojawieniem się wykwitów skórnych. Oznacza to, że faktyczna częstość występowania SDRIFE jest prawdopodobnie wyższa, niż dotychczas sądzono. Ze względu na powszechne stosowanie kotrimoksazolu w kraju rozwijającym się, jakim są Indie, pacjenci powinni mieć świadomość możliwości wystąpienia reakcji polekowej i niezwłocznie zgłaszać się do lekarza w razie wystąpienia zmian skórnych po zastosowaniu jakiegokolwiek leku.

\section{KONFLIKT INTERESÓW}

References

Autorzy nie zgłaszają konfliktu interesów.

\section{Piśmiennictwo}

1. Jones M.R., Lee H.Y.: Benign cutaneous adverse reactions to drugs. [In:] Rook's Textbook of Dermatology. C. Griffiths, J. Barker, T. Bleiker, R. Chalmers, D. Creamer (eds.). West Sussex: Wiley Blackwell Publishers, 2016, 118-5-6.

2. Mohapatra M., Panda M., Kar B.R., Raj C.: Symmetric drug-related intertriginous and flexural exanthema due to itraconazole: an uncommon side effect of a commonly used drug. Indian Dermatol Online J 2017, 8, 501-503.

3. Andersen K.E., Hjorth N., Menné T.: The baboon syndrome: systemically-induced allergic contact dermatitis. Contact Derm 1984 , 10, 97-100.

4. Häusermann P., Harr T., Bircher A.J.: Baboon syndrome resulting from systemic drugs: is there strife between SDRIFE and allergic contact dermatitis syndrome? Contact Derm 2004, 51, 297-310.

5. Nespoulous L., Matei I., Charissoux A., Bédane C., Assikar S.: Symmetrical drug-related intertriginous and flexural exanthema (SDRIFE) associated with pristinamycin, secnidazole, and nefopam, with a review of the literature. Contact Derm 2018, 79, 378-380.

6. Arnold A.W., Hausermann P., Bach S., Bircher A.J.: Recurrent flexural exanthema (SDRIFE or baboon syndrome) after administration of two different iodinated radio contrast media. Dermatology (Basel) 2007, 214, 89-93.

7. Culav I., Ljubojevic S., Buzina D.S.: Baboon syndrome/SDRIFE due to sulfamethoxazole-trimethoprim. Int J Dermatol 2013, 52, 11591160.

8. Tan S.C., Tan J.W.: Symmetrical drug-related intertriginous and flexural exanthema. Curr Opin Allergy Clin Immunol 2011, $11,313-8$.

Received: 14.06 .2020

Accepted: 15.08 .2020

Otrzymano: $14.06 .2020 \mathrm{r}$

Zaakceptowano: $15.08 .2020 \mathrm{r}$.

How to cite this article

Bhatt N., Chavan R.B., Deshmukh N.S., Belgaumkar V.A.: Symmetrical drug-related intertriginous and flexural exanthema (baboon syndrome) caused by cotrimoxazole. Dermatol Rev/Przegl Dermatol 2021, 108, 67-73. DOI: https://doi.org/10.5114/dr.2021.105897. 